ICOFOM Study Series Libraries-Archives)

\title{
Textual Danger in MLA Convergence
}

Le Risque Textuel de la Convergence

Jennifer Harris

\section{OpenEdition}

\section{Journals}

Electronic version

URL: http://journals.openedition.org/iss/687

DOI: $10.4000 /$ iss. 687

ISSN: 2306-4161

Publisher

ICOM - International Council of Museums

\section{Printed version}

Date of publication: 1 June 2016

Number of pages: $69-79$

ISSN: 2309-1290

\section{Electronic reference}

Jennifer Harris, «Textual Danger in MLA Convergence », ICOFOM Study Series [Online], 44 | 2016, Online since 06 February 2018, connection on 24 October 2019. URL : http://journals.openedition.org/iss/687 ; DOI : 10.4000/iss.687 


\title{
Textual Danger in MLA Convergence
}

\author{
Jennifer Harris \\ Curtin University - Perth Australia
}

As museums, libraries, and archives have converged, it has become a trope to say that they have returned to their original administrative grouping. Note, for example, these titles of papers on convergence: "What's old is new again" (Given \& MacTavish, 2010) and "Coming back together?" (Marcum, 2014). For some writers, the fact of their separation in the late $19^{\text {th }}$ century and into the first part of the $20^{\text {th }}$ century is the exceptional fact in the histories of these culture repositories, not their contemporary convergence. The risk inherent in such observations, especially when they are used to allay fears about convergence, is that they tend to gloss over the radical narrative changes that museums underwent in the late $20^{\text {th }}$ century. The emphasis on narrative in exhibition work and, therefore, the recognition of the textual potency of representation, ought to be among the key elements in assessing the philosophic impact of convergence. Of signal importance also is the fact that museum narratives are spatialized (Hillier \& Tzortzi, 2006; Leahy, 2012), however, this is beyond the scope of my thoughts here.

This paper argues that the implication of invoking $19^{\text {th }}$ century, and earlier, groupings of museums, libraries, and archives in the Western world as evidence for the natural alliance of what are sometimes called "memory institutions" (Robinson, 2012, p. 413) is an unwitting denial of recent museology and the textual advances of museums. This paper starts by reflecting on the historical co-existence of the three types of institution and the fact that this lends support to convergence pressures. It then examines the confusing appearance of epistemological similarities, which might suggest that convergence would not create substantial changes to their functioning. Finally, it considers the dominant role of narrative in museums, arguing that it is so fundamental a difference from the dominant work of archives and libraries that full convergence would be likely to be achieved at the high price of the loss of representation through narrative, which is one of the chief philosophical advancements of museums in the last century.

It is the potential loss of narrative as a result of convergence that looms as the chief textual danger. This paper uses text in the semiotic sense, that is, "a meaningful structure understood as being composed of signs. The meaning of a text is determined by rules (or codes)" (Edgar \& Sedgwick, 1999, p. 415). Textuality, in the semiotic sense, refers to the politics of meaning, the instability and flux of meaning generation, and the problematic dialogism of communication. Self-conscious acts of museum representation activate rich textuality. It is this paradigmatic difference between museums and the library-archive world that is at stake. The museum narrative experience is one of history plus imagination, a lyrical environment that fosters poetic engagement by visitors. It is a world of connotation, political provocation, visitor performance, and empowerment. 
By comparison, denotative acts of collecting and cataloguing are rich in a different way. I acknowledge that libraries and archives also produce exhibitions, but they are often on a much smaller scale in comparison to museum exhibitions, object-focused rather than ideafocused, only tentatively politicised, and not part of the wider narratives of the institution. The overlap of the production of exhibitions in all three institutions, therefore, is not sufficient to explain or justify convergence and fails to address the potential risk to sophisticated museum textuality.

\section{Together in the past}

One of the justifications for convergence is that this cultural movement is little more than a return to a historic, coherent approach to memory preservation, that museums, libraries, and archives were once almost indistinguishable, especially when their various elements are traced back to Renaissance cabinets of curiosities (Marcum, 2014, p. 80). Given and McTavish (2010) describe, for example, how linking the three types of institution in the UK, US, and Canada in the $19^{\text {th }}$ century was held to be good for educating the lower classes and a sign of civilization for the wider community, as also described by Hooper-Greenhill (2000, p. 14). This section considers this problematic link, first, through the historic slide together of museums and libraries via looking and reading as key pedagogical modes and, secondly, through the philosophic impact of a possible return to this approach in museum learning.

Acts of reading and learning have been highly significant in the historic merging of libraries and museums. Nineteenth century learning through a combination of looking and reading is described by Given and MacTavish (2010), who illustrate the historical process of these two pedagogical modes coming together and, through them, the gradual merging of museums and libraries. They describe the history of the Natural History Society of New Brunswick, established in 1862 , as an exemplar of $19^{\text {th }}$ century pedagogy. It started with an emphasis on the vital importance of visual contemplation of the object under study. Initially, looking was understood to reveal more knowledge than reading alone. Reading complemented looking, it did not suffice in itself.

The proponents of the natural history collections in Saint John and elsewhere similarly held that when people looked intensively at material objects they gained access to information that books could not provide. (Given \& McTavish, 2010, p. 10)

Looking, however, was later complemented by reading. Small reading rooms and book collections were established to accompany material culture collections.

The complementary understanding of reading and looking was not unusual, extending beyond natural history societies to other kinds of museums and the broader educational system in North America. In 1887, Luigi Palma di Cesnola, the first director of the Metropolitan Museum of Art in New York, argued that museums were in effect libraries of objects ... The notion that material objects could be "read" like books, even though they were ultimately distinct from printed sources, was also encouraged. (Given \& McTavish, 2010, p. 11) 
It is important to distinguish the idea of an object being "read" in the $19^{\text {th }}$ century from late $20^{\text {th }}$ century concepts of reading. In the former, the idea of reading an object encompassed the centrality of looking, as if one were reading a book, skimming its words and identifying its denotative meaning. By comparison, in the late $20^{\text {th }}$ and into the $21^{\text {st }}$ centuries, under the impact of semiotic theories, reading is philosophized as a dynamic process of meaning generation that is understood to emerge from three components, first, the original text, secondly, the engaged viewer or reader and, thirdly, the shifting contexts of production, historic meanings, and contemporary readings.

It was reading, as a process of accessing denotative meaning, that motivated the $19^{\text {th }}$ century establishment of libraries as attachments to museums. They were intended to provide background information designed to complement the knowledge gained by intense scrutiny. During the $20^{\text {th }}$ century, however, the role of the librarian and museum curator became strongly differentiated (Given \& McTavish, 2010 , p. 16), and the two types of institution eventually split with separate professional staff training.

The past differentiated institutional roles of curators are changing, while contemporary roles now draw attention to themselves. In focusing on the expression of narrative in this paper, I am choosing a key difference among these three institutions, rather than a similarity. The rise of the celebrity curator (Balzer, 2014), for example, is an emerging shared feature of art galleries and some museums, note, for example, the work and status of Hans-Ulrich Obrist in galleries and, in social history museums, the role of Fred Wilson.

The experience of many western places, however, is not connected to the new energy of the curator. The library evolved through much of the $20^{\text {th }}$ century to become a more significant and vibrant communityeducational institution than the museum, which by the mid-20 century, in many places in the Western world, was focused on research and housed static and moribund displays of objects. In the late $20^{\text {th }}$ century, museums surfaced as treasured community assets because of the rise of historical consciousness in response to impacts of globalization, tourism, and widespread valuing of material culture.

To focus on returning the three institutions to their earlier cohabitation and institutional lack of distinction is to accept implicitly the return of the museum object, philosophically, back to its pre-semiotic status. Pre-semiotically, it was understood to contain meaning quite outside reading and interpretive contexts. Robinson (2012, pp. 414415) notes that the idea of the "memory institution" has been taken up enthusiastically by policymakers, the idea of the coherence of memory being the logical glue for the three institutions, but the significance of the different styles of presentation of objects is brushed aside. There is the danger of a philosophic slip back to the pre-semiotic status of the object, book, or document as denoting meaning outside the act of reading and outside the framework of its collecting institution, that is, the home of the object would be likely to become irrelevant in interpreting the object. (What would the Mona Lisa mean outside of the Louvre?)

Robinson (2012) observes also the significant historic power of the technological innovation of digital searching in reducing the status of the object. All three types of institutions are now able to provide 
digital searches. This gives the impression of, first, similarity between types of organisations and, secondly, the transcendence of the object or document from its institutional context. The meaning of the object thus appears to be enduring, stable, and beyond interpretation.

\begin{abstract}
From this point of view, museums libraries and archives are differentiated primarily by the typological distinctions of their collections (objects, books, documents) that seem arbitrary and redundant in an age when users, with the aid of digital technologies, can bypass the institutional gatekeepers and access collections directly. (Robinson, 2012, p. 415)
\end{abstract}

Featherstone (2000), however, on contemplating the inexhaustible reach of collecting fever in the $21^{\text {st }}$ century, speculates on an archive of radical direct access and its potential to overwhelm the searcher; he calls this "disintermediation". He ponders whether the public might request the organization of material by institutions to be reinstated.

\begin{abstract}
Will disintermediation, the direct access to cultural records and resources from those outside cultural institutions, lead to a decline in intellectual and academic power or will the increased scope and complexity overwhelm the untutored user and lead to greater demands for reintermediation, involving the context framing and mapping skills of cultural intermediaries? (Featherstone, 2000, p. 166)
\end{abstract}

Writing 14 years after Featherstone, Marcum (2014), by comparison, seems to gloss over the role of cultural mediation as she focuses on the demand of users for information with no apparent interest in its source.

\begin{abstract}
For those of us concerned with the history of cultural institutions, the collaborative movement takes on an additional dimension ... We are recombining cultural resource fields and curatorial service professions that have too long been separated. (Marcum, 2014, p. 80)
\end{abstract}

For those of us who are attached to the curatorial organization of archives, libraries, and museums, there is little doubt that we would be likely to request the resumption of cultural mediation. The great ease of radically direct access to collection records suggests that a request for institutional framing of information would not be widespread. Under the impact of digital searching possibilities, therefore, the institutional contexts of collections are in danger of being disregarded. That is, the mission and philosophy of the individual institution that collected the object, book, or document could be held to be of little or no significance in meaning. The items in the collection could be seen to have slipped back to their $19^{\text {th }}$ century denotative status without the textual framing of the institution. In order to access knowledge - implicitly understood as stable knowledge - all that one would need do is look, supplemented by reading. This epistemological slip and potential intellectual loss are not widely addressed during convergence debates.

\title{
Institutional similarities
}

A rationalist epistemology, once shared by museums, libraries, and archives has been almost abandoned. Departure from this epistemology has not, however, resulted in the appearance of a shared replacement of approaches to learning, another crucial difference that is rarely taken into account in the convergence 
debate. Learning from professionally curated exhibitions, which start from the assumption that museum objects are to be approached as representational, is very different from the relatively simple provision of access to documents and books. The educational difference is possibly obscured by the fact that all three institutions usually accept semiotic theories of textuality and understand objects, books, and documents as deriving meaning from contexts - with the concept of text applying equally to objects, books, and documents. Texts are understood as politicised and unstable. It is not difficult to see, therefore, why this dramatic epistemological shift - from understanding the concept of meaning as being something that is found through denotative information, to its opposite, the volatility of textuality - has led naturally, for many people, to a broad acceptance of convergence as a natural philosophic (and happy economic) institutional fit. Volatile textuality demands an active visitor/reader. It is the conception of the visitor as a creative generator of meaning that now provides the institutional similarity for all three in practical textual terms.

A key reason for considering that convergence for the three institutional styles is appropriate emerges, therefore, from their mutual orientation to their various visitors and communities in the late $20^{\text {th }}$ and early $21^{\text {st }}$ centuries. A celebratory mood of discovering multiple post-colonial and post-modern publics has accompanied the move to converge. Extensive public programming, collections that reflect diverse publics and specific exhibitions targeted at children and minority groups have become the norm for all three.

Despite the shared approaches to visitors and reading, this paper argues that it is not sufficient to justify institutional convergence and results in neglect of fundamental textual differences. The reality is that libraries and archives take as their dominant roles the acquisition of documents, their storage, and the creation of access for visitors either in their buildings or online. Their work centres on making documents available. By contrast, museums collect and store objects, and make them broadly available when visible storage is implemented. Museums also take on another task - they create selfconscious narratives for learning as part of their everyday work.

Narratives rely on the presence and engagement of the visitor for their meaning; this is an essential difference between museums and the other two institution types. Museums are now in dialogue with their visitors (Given \& McTavish, 2010, p. 21), they set out to expose institutional choices to their visitors in a highly self-reflexive manner (Kavanagh, 2004). The role of the visitor is, therefore, tangled and complex, making convergence seem natural and common sense while also obfuscating discussion about it. In a nutshell, libraries and archives construct their work for the visitor, but museums are constructed through visitor learning. On one hand, the philosophic conception of the visitor seems to explain why convergence is a natural future state for the three institutions, but, on the other hand, reflection on the status of the active, learning visitor in museum narrative undermines arguments for convergence and their implicit assumption of stable meaning.

Strangely, this assumption sits side by side with its direct opposite, that is, the institutional acceptance of semiotics and unstable meaning. 


\title{
Museum narrative
}

The final section of this paper draws together visitor and narrative threads. I differentiate here between the deliberate narrative adopted in exhibition work and the concept of the implicit narrative. It is widely accepted by librarians and archivists that there are implicit narratives expressed through collecting and cataloguing in libraries (Robinson, 2012, p. 416) and that there is no neutrality in archiving (Cook, 2009, pp. 515-517). The fantasy of the neutrality of the collecting museum is described by Hooper-Greenhill (2000). She compares the function of maps to that of what she calls "modernist museums", that is, museums engaged in the apparent depiction of reality.

\begin{abstract}
The modernist museum depicts "reality" and shows "the way things are" in a seemingly neutral manner. Both museums and maps work through a combination of word and image. In maps, these fix a name and a shape to a place. In the modernist museum the texts next to the objects signal how the object should be viewed... Hierarchies of value are constructed, inclusions and exclusions made, the self and the other separated. Maps do this conceptually, with drawings and two-dimensional symbols. The museum does this with things, which are understood as fragments of reality itself. (HooperGreenhill, 2000, p.18)
\end{abstract}

It seems extraordinary that it was as recently as the year 2000 that such a description of museum institutions should have seemed broadly the reality - "the objectification of reality and the denial of subjectivity" (Hooper-Greenhill, 2000, p. 106). Museums, of course, continue to have implicit narratives framing their collections and catalogues and have always used artefacts in a connotative manner, wittingly or unwittingly. Powerful, creative narratives have sprung from deadpan placements of museum objects with limited descriptive labels. Implicit narratives often function below the threshold of articulation for many museum workers, for example the triumph of the nation or the social and economic progress associated with mining or agriculture.

This type of narrative is almost hidden in the protocols of collecting activity. It is very different from the deliberate storytelling undertaken by museums, often controversially, which is designed to call attention to itself; indeed, such storytelling has become the bedrock of contemporary exhibition and relies on the active role of visitors to make sense.

Robinson observes that, in recognising that while ideologies implicitly frame catalogues in all three institutions, "it is problematic to equate them with curatorial interventions applied to museum collections ... only museums ... actively and self-consciously author historical narratives through their objects" Robinson (2012, p. 423). Museum exhibition narrative starts from the lyrical ideal that museum work is about representation, that it is not limited by denotation, and that material culture can be used imaginatively to tell stories. I now turn to the central issue of the place of self-conscious museum narrative in the MLA convergence project.

Just as the attachment of libraries to museums in the $19^{\text {th }}$ century led to the atrophying of museums (Given \& McTavish, 2010), so danger looms again. In the $19^{\text {th }}$ century, libraries and museums worked from the same basic epistemology, but once the role of reading in 
education was elevated over observation, the fading of museums in community intellectual life commenced. Now, with MLA convergence, the danger is that the leap museums have taken into provocative narrative could be reversed under the pressure to conform to the style of collecting and cataloguing undertaken by libraries and archives. The fact that some commentators regard convergence as unproblematic reveals that they have not observed the differences between museums and other memory institutions.

Although it is evident that catalogues order experience, a different kind of ordering is found in the experience of exhibition narratives. Hetherington (2006) argues that it was the experience of modernity that was the focus of the museum at the end of the $18^{\text {th }}$ century. Many writers trace the multiple lines of museum evolution through a variety of pre-existing institutions, but Hetheringon says that

it is its direct engagement with issues of experience (whether that be the experience of art, history, civilisations, ethnographic encounter or locality expressed in material cultural form) that marks it out as something new. (Hetherington, 2006, p. 599)

Hetherington draws on Benjamin's (1973a; 1973b) and Koselleck's (2004) distinction between, on the one hand, the broad sense of an experience of life's wholeness that was characteristic of the premodern experience and, on the other, the experience of fragmentation that is characteristic of modernity. Some of this analysis was pre-dated by Nora's (1989) work on the sensation of being ripped from an everyday environment of memory and Harvey's (1989) discussion of time-space compression: the experience of the crushing of space as an effect of globalization and the loss of time through the speed of communication and travel. Hetherington (2006, p. 600) describes the awesome loss of "a shared topos in which a community existed as a knowable whole to its members" and the disorientation that followed that loss, a disorientation that we all struggle with every day. In the past, he says,
people dwelt in this shared topos in a time that was perceived to be continuous and natural and were able to experience the present as a present. There was no sense of emergence, trajectory or novelty in such experience... With modernity comes disruption of the social relations that underpin such a form of experience. (Hetherington 2006, p. 600)

One of our central responses to this crisis, according to Hetherington (2006, p. 600), has been a "shift from natural to historical time ... as cultural understanding seeks to reorientate itself to radically changed circumstances". Western museums' play with narrative through material culture has been one of the most powerful ways that this time shift has been expressed.

\footnotetext{
The museum is one of the key modern institutions in which this sense of experience as lack and disconnection from a natural topos is addressed... it seeks through its display regimes, their narratives and ordering logics to provide people with a sense that they are living in a world where our uncertain and complex set of experiences make sense. (Hetherington, 2006, p. 600)
}

Museums of social history work with everyday objects, solid and palpable in their physicality, to address "this sense of experience as 
lack". Visitors can see that the objects have endured, surviving from times of coherent community experience. The historical structuring and arrangement of the objects gives reassurance that there is still some order in the world. Although many museums now seem to prioritize ideas over objects, see, for example, as long ago as Vergo (1989), it is in fact material, mostly non-documentary, culture that creates the first difference between museum exhibitions and other institutions. Narratives are produced through the touchstone of material culture, giving visitors both the solidity of objects and the creative, speculative intangibility of narrative explorations. Visitors are invited to use their imaginations and memories to amplify curatorial stories, producing personalized, often politicised meanings.

Nascent responses to the fracturing experience of modernity appeared in museums in the early $19^{\text {th }}$ century. Pearse (2007), for example, uses the concept of spectacle to describe William Bullock's Egyptian Hall, also known as London Museum or Bullock's Museum at 22 Piccadilly, London. This English example is used here to illustrate the beginning of self-conscious narrative-based exhibition. The Egyptian-inspired building was erected in 1812 and used for natural history display, but Bullock had displayed animals before this time. He used the Linnaean classification system to order his taxidermy animals with accompanying catalogue numbers, but seems to have been subject to visitors' complaints.

\begin{abstract}
From the viewer's perspective, this would have been confusing not only because of the need to understand the system itself, but also because Bullock's presentation of it must have been inevitably bitty and disjointed, given the large gaps in his collection. He needed to please his public, and matching numbers on the objects and in the catalogue Companion proved much more intelligible. (Pearse, 2007, p. 17)
\end{abstract}

In other ways also, Bullock needed to soften the rigidity of the Linnaean system in order to please his public. Naturalistic settings were created, still knowable to us today from an aquatint of 1810 .

Five ceiling-height artificial trees, one a coconut palm, are dotted about; two of the trees have very large snakes twined up them and two have birds in their branches. Between the trees stand large animals and birds, including an elephant, a zebra, a bear, a kangaroo and at least four birds including what seems to be a black swan. (Pearse, 2007, p. 18)

Ironically, the settings were accompanied by juxtapositions of animals that would be impossible outside the worlds of taxidermy and zoos. So, on one hand, Bullock began to produce a narrative of exotic vegetation and animal interaction but, on the other, grouped the animals more or less scientifically. He also produced more deliberate narratives; the evidence for this is from a surviving display of a fighting tiger and a large snake. The snake, a Python reticulates, is 5.7 metres long (Pearse, 2007, p. 24). Although this is the correct length for a python, it was achieved by Bullock for the exhibition by the joining of two specimens. Further artificiality is evident in the fact that the python's head is carved from wood. Pearse $(2007$, p. 24) says that Bullock was sometimes forced to use composites and to manufacture them in order to create "a show that was as complete as possible" in a taxonomic sense. He must also have felt pressured to depart from a strict Linnaean order because he was unable to show a complete display of animals due to gaps in his collection. He seems 
to have been driven, therefore, by visitor expectations of two discursively different elements: classification completeness and, simultaneously, high drama. The violent interlocking of the tiger and the python, reproduced in a terrifying photograph by Pearse (2007, p. 25), elicits dread from the viewer as one imagines being caught in the ferocious jaws. The visitor, therefore, is inserted into the drama and invited to respond imaginatively.

The example of Bullock's Museum and numerous others show that the world of fairground drama was an inspiration to English museums in the early $19^{\text {th }}$ century. With the progress of science throughout the $19^{\text {th }}$ century in Europe, however, narratives became muted as they were replaced with displays of rigid taxonomies.

Narratives re-emerged strongly in the late $20^{\text {th }}$ century, a timing coincident with the disrupting experience of the fragility of modernity described by Hetherington (2006) as one of the hallmarks of contemporary culture. Museum narratives adapted especially well to the demands of the exhibition of post-colonialism, a central disruptive experience of modernity. Contemporary museum narratives are able to cover broad historical periods while providing often heart-rending emotionality through breakouts from the main narrative to include individual stories of particular people. The individual stories illustrate the broader story by providing colourful detail and also foster visitor engagement with historical characters on a human level. The textual move between general histories of, for example, nation building, conquest, forced migration, environmental destruction, and so on are accompanied by stories of specific, individual people. This steady movement between the generality of history and the particularity of individual people has become an established museological rhythm and engages visitors powerfully at an emotional level.

The plethora of historical films and novels also appears to address the bedevilling time shifts of modernity, identified by Hetherington. Television particularly is full of historical series; noteworthy is Downton Abbey, a six-season UK series that charts the collapsing power of the British aristocracy in the $20^{\text {th }}$ century. Following on from Hetherington's comment that the museum is positioned uniquely through its narrative style to address the fragility of modern experience, one needs to query why novels and films do not also take on the role. It is beyond the scope of this paper to address this question in detail, but it is important to note that the pressure of realism as the contemporary mode of storytelling floods film and novel narratives. Realism offers a reassuring sense of closure. Closure, however, tends to draw a line under the story, as if the characters' experiences are co-terminus with the events. As the story draws to an end, the chief characters' conflicts are resolved. The family at the heart of Downton Abbey, for example, provides the textual focus for the closure of realism. Although the characters have uncertain fortunes, our riding of those fortunes with them has the textual effect of reducing our experience to the experience of the characters, despite the script's attention to significant historical events. This is because our emotional involvement with individual characters is often more intense in realist texts than our need to use their stories to make sense of the wider world. Our identification with the characters also tends to reduce the likelihood of us taking the narrative experiences beyond the world of the story. Our emotional involvement can have the effect of reducing political awareness. This is a most restrictive aspect of realism if one wishes to use realist narrative to foster political engagement. 
Although Hetherington notes that museum narratives tackle uncertainty while providing reassurance to the visitor, they do not do so through the emotional closure characteristic of the realism of films and novels. By contrast, the world of the museum narrative is one of provocation. Museums' narrative forces us to look beyond the museum and, in idealized circumstances, become politically alive.

Museum representation through narrative is unlike any other, despite its discursive links: to cinema and theatre in terms of public performance; to fairgrounds in terms of the experience of shock and awe; to shopping in terms of the inspection of objects; and to all of these in terms of performative demands on the visitor. Museum narrative elicits emotional engagement with a lyrical, poetic dimension set against historical events. Recognition of the fact of representation cuts across curatorial domination and empowers visitors to interrogate museum stories.

\section{Conclusion}

The visitor is celebrated by archives, libraries, and museums. Further, all three institution types concur: visitors/readers are fundamental to the generation of meaning. These are significant philosophic similarities. The role of visitors in the exhibition narrative process, however, highlights the core difference between museums and their companion memory institutions. At the heart of the narrative process is the work of representation. Museum curators grasp that their work is focused on representation, particularly in a deliberate and self-conscious way as expressed via narrative. Museum narrative, with its multiple poetic possibilities, offers communities a bulwark against the authoritarianism that is threatened in a dominant curatorial voice. The narrative process helps institutions to guard against the loss of institutional identity (Parker, 2011, p. 187), encourages diverse interpretations, and empowers individual visitors.

How ironic that museums should undergo pressure in the early $21^{\text {st }}$ century to converge with libraries and archives, after having gone through the long process of separating themselves from the other two and finding another way to present their collections. The spectacular rise of self-conscious museum narrative has been a vast achievement in textual terms. Further convergence would be likely to be a retrograde step.

\section{References}

Balzer, D. (2014). Curationism: How Curatoring Took Over the Art World and Everything Else. Toronto: Coach House Books.

Benjamin, W. (1973a).The storyteller.In Illuminations. (pp. 83-107). London: Fontana.

Benjamin, W. (1973b).On some motifs in Baudelaire.In Illuminations. (pp.152-196).London:Fontana.

Cook, T. (2009). The archive(s) is a foreign country: historians, archivists and the changing archival landscape. The Canadian Historical Review, 90(3), 497-534.

Edgar, A., \& Sedgwick, P. (Eds.). (1999). Cultural Theory: The Key Concepts. London: Routledge.

Featherstone, M. (2000).Archiving cultures.The British Journal of Sociology, 51(1), 161-184.

Given, L., \&McTavish, L. (2010). What's old is new again: the reconvergence of libraries, archives and museums in the digital age. The Library Quarterly: Information, Community, Policy, 80(1), 7-32. 
Harvey, D. (1989). The Condition of Post-Modernity: An Enquiry into the Origins of Cultural Change. Oxford: Basil Blackwell.

Hetherington, K. (2006). Museum. Theory, Culture and Society, 23(2-3), 597603.

Hillier, B., \&Tzortzi, K. (2006). Space syntax: the language of museum space. In Macdonald, S. (Ed.). A Companion to Museum Studies. (pp. 282-301). Maldon, Oxford and Carlton: Blackwell Publishing.

Hooper-Greenhill, E. (2000). Museums and the Interpretation of Visual Culture. London: Routledge.

Kavanagh, G., (2004). Melodrama, pantomime or portrayal?: Representing ourselves and the British Past through exhibitions in history museums. In Carbonell, B. (Ed.).Museum Studies: An Anthology of Contexts. (pp. 348-355). Oxford: Blackwell Publishing.

Koselleck, R. (2004). Futures Past. New York: Columbia University Press.

Leahy, H. (2012). Museum Bodies: The Politics and Practices of Visiting and Viewing. Farnham: Ashgate Publishing Ltd.

Marcum, D. (2014). Archives, libraries, museums: Coming back together? Information and Culture: A Journal of History, 49(1), 74-89.

Nora, P. (1989). Between memory and history: Les lieux de memoire. Representations, 26, 7-25.

Parker, S. (2011).Convergence of archives, libraries and museum.IFLA Journal, 37(3), 187-8.

Pearse, S. (2007). William Bullock: Inventing a visual language of objects. In S. Knell, S. MacLeod \& S. Watson (Eds.).Museum Revolutions: How Museums Change and are Changed. (pp. 15-27). London and New York: Routledge.

Robinson, H. (2012). Remembering things differently: Museums, libraries and archives as memory institutions and the implications for convergence.Museum Management and Curatorship, 27(4), 413-429.

Vergo, P. (1989). The New Museology. London: Reaktion Books.

\section{Abstract}

The convergence of museums, libraries, and archives challenges museums to maintain their insistence on the intellectual gains to be derived from selfconscious representation through exhibition narrative. Confusingly, all three types of institution have a rationalist epistemological background, and all three now work from an epistemology of unstable, politicised meaning. The similarities, however, mask significant differences. Although all three institutions collect and catalogue, the deliberate acts of representation that are undertaken by museums in the construction of narratives mark museums out as fundamentally different. This paper argues that museums have changed paradigmatically, moving away from their long-term institutional companions. Convergence is likely to endanger the textual advances that museums have achieved.

Key words: convergence, narrative, rationalist epistemology, representation

\section{Résumé \\ Le Risque Textuel de la Convergence}

La convergence des musées, bibliothèques et archives constitue pour les musées un défi de maintenir leur insistance sur les acquis intellectuels que l'on dérive de la représentation consciente à travers le tissu narratif d'une exposition. Le fait que ces trois types d'institutions soient issus d'une tradition rationaliste épistémologique et que toutes trois opèrent maintenant à partir d'une épistémologie au sens instable et politisé, est une source de confusion. Ces similarités masquent cependant des différences significatives. Bien que ces trois institutions collectionnent et cataloguent, les actions de représentation entreprises par les musées pour construire leurs récits en font des institutions fondamentalement différentes. Cet article soutient que les musées ont changé de façon paradigmatique, se démarquant de leurs compagnons institutionnels de toujours. Une convergence aurait toutes les chances de menacer les avancées textuelles faites par les musées.

Mots clés: convergence, récit, épistémologie rationaliste, représentation. 